\title{
Migraciones y nuevos modos de pensar en la identidad contemporánea: Representaciones fílmicas en un mundo globalizado Proyecto de Investigación $\mathrm{N}^{\circ} 14.2$
}

Equipo de Investigación ${ }^{(1)}$

Zulema Marzorati y Mercedes Pombo por Facultad de Diseño y Comunicación, Universidad de Palermo (ARG)

\begin{abstract}
Resumen: El Proyecto de Investigación 14.2 presenta un espacio de reflexión en relación a las representaciones colectivas y la conformación de los imaginarios sociales. El cine es un documento social que propone multiplicidad de miradas sobre las mentalidades de una época o lugar. A través de sus historias y sus modos de presentarse es factible comprender las reglas y discursos que imperan en la actualidad. Se propone analizar de qué manera se manifiesta el concepto de globalización en diversos momentos de la historia y desde diferentes ópticas, siempre utilizando el cine como motor de abordaje. Lo que buscan estas investigaciones es complejizar el concepto y sus formas de presentarse en las representaciones fílmicas, abordando sus consecuencias como un abanico que despliega otros modos de entender a las sociedades. Esto conduce a reflexionar acerca de las migraciones y los nuevos paradigmas que se manifiestan en la construcción de la identidad contemporánea. La otredad como concepto alejado de nuestra vida cotidiana va perdiendo espacio, dando lugar a la conformación de nuevos actores y relaciones sociales.
\end{abstract}

Palabras claves: Cine - representaciones - globalización - identidad - memoria - sociedad - etnicidad.

[Resúmenes en inglés y portugués en la página 164]

${ }^{(1)}$ Los CVs del Equipo de Investigación pueden consultarse en el Capítulo Directores de Líneas y Coordinadores de Proyectos de esta misma Edición. 


\section{Acerca del Proyecto 14.2}

\section{Migraciones y nuevos modos de pensar en la globalización contemporánea: Representaciones fílmicas en un mundo globalizado}

El Proyecto 14.2 Migraciones y nuevos modos de pensar en la globalización contemporánea: Representaciones fílmicas en un mundo globalizado reúnen y proponen a través de distintos films y propuestas narrativas, una visión del mundo y de las transformaciones sociales en cuanto al concepto de globalización, migraciones e identidad. La propuesta consiste en analizar algunos de estos acontecimientos mediante el abordaje de los procesos estéticos y simbólicos del imaginario social y sus representaciones fílmicas. El siglo XX ha sido considerado por Eric Hobsbawm como la era de las catástrofes sociales, pero al mismo tiempo, la era de los más grandes progresos en la historia de la humanidad, con cambios revolucionarios de profundas repercusiones a nivel mundial. El cine se presenta como un lenguaje artístico que pone en evidencia muchos de estos procesos, permitiendo reflexionar y tener una mirada consciente y crítica sobre ellos.

Avanza en una investigación en la que participan académicos de diversas Instituciones con la coordinación compartida de Zulema Marzorati (UP) y Mercedes Pombo (UP) con el fin de generar un análisis de un corpus de imágenes fílmicas documentales y de ficción, que permitan el abordaje de la intersección cine/sociedad en relación con su contexto de producción. Los films son productos culturales que toman elementos del universo simbólico que los rodea, constituyéndose como constructores y reproductores de imaginarios sociales.

Las reflexiones y los resultados obtenidos en el Proyecto 14.2 Migraciones y nuevos modos de pensar en la identidad contemporánea, se continúan desarrollando en el Proyecto 14.3 Cine, memoria y género, una perspectiva en crecimiento, en el marco de la misma Línea de Investigación y bajo la misma Directora Zulema Marzorati (UP).

Sus principales objetivos son:

- Analizar los cambios históricos y cómo fueron representados por la producción cinematográfica en su carácter de creadores y reproductores de identidades y del imaginario social

- Reflexionar sobre las transformaciones sociales, políticas y culturales que se generan en las distintas sociedades a partir del proceso de migraciones

\section{Acerca de la Línea 14}

Cine e Historia: Reflexiones sobre la imagen política en el cine contemporáneo dirigida por Zulema Marzorati y Mercedes Pombo se desarrolla de manera ininterrumpida desde 2015 en la Facultad de Diseño y Comunicación (UP, Argentina), e incluye hasta el momento seis proyectos finalizados el 14.1 Cine e Historia: Reflexiones sobre la imagen política en el cine contemporáneo, el 14.2 Migraciones y nuevos modos de pensar en la identidad contemporánea ambos coordinados por Zulema Marzorati (UP) y Mercedes 
Pombo (UP); el 14.3 Cine, memoria y género, una perspectiva en crecimiento coordinado por Zulema Marzorati y Mercedes Pombo (UP) y Claudia Bossay (Universidad de Chile, Chile); el 14.4 Narrativa y Género: El camino de la Heroína, el arquetipo femenino universal para un nuevo paradigma, coordinado por Gabriel Los Santos y Tomás Stiegwardt (UP) y Marcelo Sabatés, Gabriela Díaz de Sabatés y Carolina Posse Emiliani (Columbia College Chicago, EEUU); el 14.5 Violencia física y simbólica. Algunas reflexiones desde el audiovisual y sus discursos coordinado por Zulema Marzorati y Mercedes Pombo (UP), y Alejandra Rodríguez (Universidad Nacional de Quilmes, Argentina); y el 14.6 El camino de la Heroína: narrativa, género y diversidad, coordinado por Gabriel Los Santos y Tomás Stiegwardt (UP) y Marcelo Sabatés, Gabriela Díaz de Sabatés y Carolina Posse Emiliani (Consulate General of Argentina in Chicago, EEUU).

\section{Mapa de Áreas y Proyectos}

El Proyecto 14.2 se vincula con todas carreras de grado y posgrado, dado que impacta en la incorporación de la investigación en la lógica de la docencia universitaria, y en la actualización de los contenidos y competencias de la de las carreras de la Facultad, particularmente en las de posgrado: Maestría en Gestión del Diseño y Doctorado en Diseño. Específicamente guarda relación con las carreras que tienen que ver con la imagen: Dirección de Actores de Cine y TV, Dirección de Arte de Cine y TV, Guión de Cine y TV, Licenciatura en Comunicación Audiovisual, Licenciatura en Dirección Cinematográfica, Licenciatura en Fotografía, Licenciatura en Televisión y Producción de Televisión.

\section{Productos y Resultados}

\section{a)- Publicaciones}

Cuaderno del Centro de Estudios de Diseño y Comunicación No77. (2019) Cine y sociedad. Representaciones fílmicas en un mundo globalizado. Coordinación Zulema Marzorati y Mercedes Pombo. Año XI, Diciembre 2019, Buenos Aires, Argentina. ISSN: 16680227. Esta publicación documenta y comunica los resultados alcanzados en el proyecto de investigación 14.2 Migraciones y nuevos modos de pensar en la identidad contemporánea, y a continuación se detallan los autores y artículos contenidos en ella:

Marzorati, Zulema; Pombo, Mercedes (2019) Prefacio (Pp. 11-16)

Tal, Tzvi (2019) Brechas y etnicidad. Personajes judíos violentos en películas de Argentina, Uruguay y Venezuela (Pp. 17-27)

Rodríguez, Alejandra F. (2019) ¿Dónde está el sujeto?: problemas de representación de los pueblos originarios en el cine (Pp. 29-43)

Gruber, Mónica Leyendo la realidad desde el cine. Imagen femenina y juventud en los últimos films de Pedro Almodóvar (Pp. 45-60)

Stagnaro, Adriana A. (2019) Lo imaginario y lo maravilloso de Internet. Una aproximación antropológica (Pp. 61-72) 
Marzorati, Zulema; Pombo, Mercedes (2019) Humanismo y solidaridad en El puerto (Kaurismäki, Finlandia/ Francia/ Alemania, 2011) (Pp. 73-84)

Stella, María Elena (2019) Holocausto y memoria en los tiempos de la globalización. Representaciones en el cine alemán (Pp. 85-94)

Bossay P, Claudia (2019) Libertadores; bicentenarios de las independencias en el cine (Pp. 95-117)

Casale, Marta N. R. (2019) La imagen faltante, de Rithy Panh, testigo y cineasta. El genocidio en primera persona (Pp. 119-131)

Actas de Diseño No24. (2018) XII Encuentro Latinoamericano de Diseño "Diseño en Palermo". Foro de Escuelas de Diseño - XI Plenario 2017, VIII Congreso Latinoamericano de Enseñanza del Diseño. II Coloquio de Investigación y Desarrollo en Diseño Latino. Coloquio de Investigación. Julio 2017, Buenos Aires, Argentina. En esta publicación se documentan las ponencias presentadas en la Comisión de la Línea de Investigación No14: Cine y sociedad. Reflexiones sobre el cine contemporáneo: Proyecto 14.2 Migraciones y nuevos modos de pensar en la identidad contemporánea: Representaciones fílmicas en un mundo globalizado en el II Coloquio de Investigación y Desarrollo en Diseño (Pp. 41-42).

\section{b)- Congresos / Coloquios / Plenarios}

$2^{\circ}$ Plenario de Directores de Investigación DC, 27 de agosto y 4 de septiembre - 2018. Es este segundo plenario los Directores de las Líneas y Proyectos de Investigación presentaron a sus pares y al conjunto del Programa de Investigación de la Facultad de Diseño y Comunicación, los resultados obtenidos y/o en proceso (publicaciones y acuerdos), junto con los avances de Proyectos.

La Directora de la Línea de Investigación No14 expuso las conclusiones del Proyecto 14.2 Migraciones y nuevos modos de pensar en la identidad contemporánea (finalizado) y su producto el Cuaderno No77 de reciente publicación, y la apertura del Proyecto 14.3 Cine, memoria y género, una perspectiva en crecimiento.

III Coloquio de Investigación y Desarrollo en Diseño Latino. Universidad de Palermo, 30 de julio de 2018. IX Congreso Latinoamericano de Enseñanza del Diseño. Semana Internacional del Diseño en Palermo.

En la comisión Cine y sociedad se presentaron las reflexiones y conclusiones del proyecto 14.2 Migraciones y nuevos modos de pensar en la identidad contemporánea, junto con su producto el Cuaderno No77 sobre las migraciones y el proceso de globalización documentado cinematográficamente. El siglo XX ha sido considerado la era de las catástrofes sociales y los grandes progresos, con cambios revolucionarios de profundas repercusiones a nivel mundial. Forman parte de estas transformaciones, el desarrollo de la globalización neoliberal, las migraciones y las nuevas formulaciones de identidad. Dado que la globalización constituye una integración que relaciona pueblos y países del mundo, el trabajo explora una de sus principales consecuencias: las migraciones, que posibilitan los flujos de personas a través de las fronteras, que constituyen una nueva etapa de las transformacio- 
nes internacionales. Expusieron: Claudia Bossay, Marta Casale, Mónica Gruber, María Paz Peirano, Mercedes Pombo, Zulema Marzorati, Alejandra Rodríguez, Adriana Stagnaro, Maria Elena Stella, Lizel Tornay y Victoria Alvarez Tornay.

A continuación se detallan las ponencias presentadas en esta Comisión coordinada por la Directora del proyecto Zulema Marzorati:

Claudia Bossay

La mujer en el audiovisual sobre la colonia chilena, el caso de la Quintrala

Claudia Bossay

Libertadores: bicentenarios de las independencias en el cine

Marta Casale

La imagen faltante, de Rithy Panh, testigo y cineasta. El genocidio en primera persona Mónica Gruber

Leyendo la realidad desde el cine. Imagen femenina y juventud en los últimos films de Pedro Almodóvar

Mónica Gruber

Reflexiones sobre la construcción de la imagen femenina. La voz dormida: de Dulce Chacón a Benito Zambrano

Maria Paz Peirano

FEMCINE: cine de mujeres y nuevas formas de representación en el campo cinematográfico chileno

Mercedes Pombo, Zulema Marzorati

Humanismo y solidaridad en El puerto (Kaurismäki, Finlandia/Francial Alemania, 2011)

Mercedes Pombo, Zulema Marzorati

Memoria, olvido y perdón en la Gran Guerra. El universo femenino en Frantz (Ozón, 2017)

Alejandra Rodríguez

El discurso histórico audiovisual, entre la academia y la divulgación. Nuevas producciones sobre los pueblos originarios en la historia

Alejandra Rodríguez

¿Dónde está el sujeto?: problemas de representación de los pueblos originarios en el cine

Adriana Stagnaro

Lo imaginario y lo maravilloso de Internet. Una aproximación antropológica

María Elena Stella

Holocausto y memoria en los tiempos de la globalización. Representaciones en el cine alemán

Lizel Tornay, Victoria Álvarez Tornay

Campo de Batalla. Cuerpo de Mujer. Representaciones y sensibilidades 


\title{
c)- Formación de Posgrado e Impacto curricular
}

La Directora Zulema Marzorati es Docente de Posgrado en Diseño de la Facultad de Diseño y Comunicación en Maestría en Gestión del Diseño y Doctorado en Diseño, y al igual que la Coordinadora Mercedes Pombo (UP), incorporan los contenidos de su investigación a sus asignaturas de posgrado.

\section{Evaluación Externa}

El Proyecto 14.2 Migraciones y nuevos modos de pensar en la identidad contemporánea, cuyos resultados fueron publicados en el Cuaderno $\mathrm{N}^{\circ} 77$, fue evaluado exitosamente por los Evaluadores Amanda López y Javier de Ponti en 2019.

\begin{abstract}
Research Project 14.2 presents a space for reflection in relation to collective representations and the conformation of social imaginaries. Cinema is a social document that proposes a multiplicity of views on the mentalities of a time or place. Through their stories and their ways of presenting themselves, it is possible to understand the rules and speeches that prevail today. It is proposed to analyze how the concept of globalization manifests itself at various moments in history and from different perspectives, always using the cinema as a motor of approach. What these investigations seek is to make the concept and its ways of presenting itself in filmic representations more complex, addressing its consequences as a range that displays other ways of understanding societies. This leads us to reflect on migrations and the new paradigms that are manifested in the construction of contemporary identity. Otherness as a concept far removed from our daily life is losing space, giving rise to the formation of new actors and social relationships.
\end{abstract}

Keywords: Cinema - representations - globalization - identity - memory - society - ethnicity.

Resumo: O Projeto de Pesquisa 14.2 apresenta um espaço de reflexão em relação às representações coletivas e à conformação dos imaginários sociais. $\mathrm{O}$ cinema é um documento social que propõe uma multiplicidade de olhares sobre as mentalidades de um tempo ou lugar. Por meio de suas histórias e de suas formas de se apresentar, é possível compreender as regras e os discursos que prevalecem hoje. Propõe-se analisar como o conceito de globalização se manifesta em vários momentos da história e sob diferentes perspectivas, sempre utilizando o cinema como motor de abordagem. O que essas investigações buscam é tornar mais complexos o conceito e suas formas de se apresentar nas representações fílmicas, abordando suas consequências como uma gama que expõe outras formas de compreender as sociedades. Isso leva a refletir sobre as migrações e os novos paradigmas que se manifestam na construção da identidade contemporânea. A alteridade como conceito 
distante do nosso cotidiano vai perdendo espaço, dando lugar à formação de novos atores e relações sociais.

Palavras chave: Cinema - representações - globalização - identidade - memória - sociedade - etnia.

[Las traducciones de los resúmenes fueron realizadas a través de traductor automático] 